\title{
On the relationship between large-scale climate modes and regional synoptic patterns that drive Victorian rainfall
}

\author{
D. C. Verdon-Kidd ${ }^{1,2}$ and A. S. Kiem ${ }^{2}$ \\ ${ }^{1}$ Sinclair Knight Merz, Newcastle, New South Wales, Australia \\ ${ }^{2}$ Environmental and Climate Change Research Group, School of Environmental and Life Sciences, University of Newcastle, \\ New South Wales, Australia
}

Received: 28 August 2008 - Published in Hydrol. Earth Syst. Sci. Discuss.: 10 October 2008

Revised: 13 January 2009 - Accepted: 25 March 2009 - Published: 7 April 2009

\begin{abstract}
In this paper regional (synoptic) and large-scale climate drivers of rainfall are investigated for Victoria, Australia. A non-linear classification methodology known as self-organizing maps (SOM) is used to identify 20 key regional synoptic patterns, which are shown to capture a range of significant synoptic features known to influence the climate of the region. Rainfall distributions are assigned to each of the 20 patterns for nine rainfall stations located across Victoria, resulting in a clear distinction between wet and dry synoptic types at each station. The influence of large-scale climate modes on the frequency and timing of the regional synoptic patterns is also investigated. This analysis revealed that phase changes in the El Niño Southern Oscillation (ENSO), the Indian Ocean Dipole (IOD) and/or the Southern Annular Mode (SAM) are associated with a shift in the relative frequency of wet and dry synoptic types on an annual to interannual timescale. In addition, the relative frequency of synoptic types is shown to vary on a multi-decadal timescale, associated with changes in the Inter-decadal Pacific Oscillation (IPO). Importantly, these results highlight the potential to utilise the link between the regional synoptic patterns derived in this study and large-scale climate modes to improve rainfall forecasting for Victoria, both in the short- (i.e. seasonal) and long-term (i.e. decadal/multi-decadal scale). In addition, the regional and large-scale climate drivers identified in this study provide a benchmark by which the performance of Global Climate Models (GCMs) may be assessed.
\end{abstract}

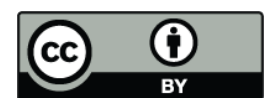

Correspondence to: D. Verdon-Kidd (dkidd@skm.com.au)

\section{Introduction}

Managing a highly variable climate alongside increasing demand for natural resources represents one of the most significant challenges for sustainable water resources management in many parts of the world. Australia, where the rainfall and streamflow regimes rank among the most variable, is no exception (e.g. McMahon, 1987; Nicholls et al., 1997). This variability occurs over a number of timescales, from annual through to multi-decadal (and possibly longer). An epoch of elevated rainfall and streamflow is known to have occurred during the mid-1940's through to the mid-1970's across much of eastern Australia, while the mid-1970's were associated with a return to drier conditions for both northeastern and Western Australia (e.g. Erskin and Warner, 1988; Franks and Kuczera, 2002). The phenomenon responsible for these multi-decadal step changes in climate is known as the Pacific Decadal Oscillation (PDO) (Mantua et al., 1997) or the Inter-decadal Pacific Oscillation (IPO) (Power et al., 1999). The PDO and IPO represent variable epochs of warming (i.e. positive phase) and cooling (i.e. negative phase) in both hemispheres of the Pacific Ocean (Folland, 2002) and are known to influence climate patterns around the world (e.g. Kiem et al., 2003; Kiem and Franks, 2004; Verdon et al., 2004; Zanchettin et al., 2008). Importantly the IPO/PDO has been found to be a dominant climate mode in the Pacific sector since at least the 15th Century (Verdon and Franks, 2006) and is therefore likely to continue to influence climate in the future.

More recently, it appears that during the mid-1990's southeastern Australia, in particular Victoria, experienced a step change towards a drier climate, resulting in lower than average rainfall and streamflows over the past decade, placing

Published by Copernicus Publications on behalf of the European Geosciences Union. 
significant strain on water resources in the region (e.g. Timbal and Jones, 2008). The physical mechanisms behind this step change are not yet completely understood. However, studies conducted as part of the South Eastern Australia Climate Initiative (SEACI) suggest that changes in the location and intensity of the Subtropical Ridge may play a role in the reduction in southeast Australian rainfall (e.g. Drosdowsky, 2005; Murphy and Timbal, 2007, and the references therein). Furthermore, a recent study by Kiem and VerdonKidd (2009) has shown that the combined influence of the El Niño/ Southern Oscillation (ENSO) in the Pacific Ocean sector and the Southern Annular Mode (SAM) over the southern extratropics is at least partially responsible for the reduction in rainfall.

Given the heavy reliance on fresh water for consumptive, agricultural, industrial and recreational use in Australia, there is a clear need to better understand what drives climate variability on annual through to multi-decadal scales. Ultimately, identifying and understanding natural climate drivers is crucial to the successful development of seasonal forecasting schemes, risk assessments associated with climate impacts, and adaptation response frameworks - particularly if projected impacts of anthropogenic climate change manifest through alterations to the frequency, location and/or intensity of the natural drivers.

The subject area of this study, Victoria, is influenced by a range of regional synoptic systems and large-scale climate phenomena due to its relative location to the Pacific, Indian and Southern Oceans. Wright (1989) and Pook et al. (2006) identified a number of regional synoptic weather systems that are related to rainfall in the cool season (April-October) in north-western Victoria, including frontal systems (generated out of the Southern Ocean), cut-off lows and easterly dips. Other studies have shown that a number of large-scale climate phenomena also influence the variability of Victoria's climate on an annual to inter-annual timescale, including the ENSO (e.g. Ropelewski and Halpert, 1987; Stone and Auliciems, 1992; Power et al., 1998, Verdon et al., 2004), Indian Ocean Dipole (IOD, e.g. Nicholls, 1989; Ashok, 2003; Verdon and Franks, 2005), and SAM (e.g. Meneghini et al., 2007). However, it is difficult to analyse and interpret the impacts of the large-scale climate phenomena (i.e. ENSO, SAM, IOD) on Victorian rainfall due to the complex interaction between these modes. Unlike the rest of eastern Australia which is clearly influenced by ENSO, no clear relationship can be found between Victorian rainfall and any individual large-scale climate mode (Kiem and Verdon-Kidd, 2009). Therefore in order to improve our insights into climate variability in Victoria it is necessary to understand both interactions between the large-scale climate drivers (i.e. ENSO, IOD and SAM) and the influence of these modes on the regional synoptic patterns that actually deliver the rainfall.

This paper aims to identify the key regional synoptic patterns that are related to rainfall variability in Victoria and to determine how the regional patterns are modulated by the large-scale climate modes (including IPO, ENSO, IOD and $\mathrm{SAM})$. A technique known as self-organizing maps (SOM) is adopted to identify the key regional synoptic patterns for Victoria. The SOM methodology has been shown to be successful in identifying key regional synoptic patterns that drive local climate in other regions of the world (e.g. Cavazos, 2000; Cavazos et al., 2002; Hewitson and Crane, 2002; Hope et al., 2006; Reusch et al., 2007). Importantly, the SOM methodology is less subjective than other forms of pattern recognition and the non-linear approach lends itself to regions where local climate is constantly changing due to large-scale climate variability. The SOM methodology is applied to monthly sea level pressure (SLP) data from 1948 through to 2007 to identify 20 key regional synoptic types relevant to Victoria. The link between these synoptic patterns and Victorian rainfall is then assessed, followed by an analysis of the relationship between large-scale climate phenomena and the frequency of occurrence of the key regional synoptic patterns.

\section{Data}

\subsection{Sea level pressure data}

Monthly global sea level pressure (SLP) data was obtained from the US National Oceanic and Atmospheric Administration (NOAA) to develop the SOM. The SLP data set (NCEP/NCAR Reanalysis) comprises global monthly pressure data for the years 1948 to present (this study used pressure data from January 1948 to April 2007). This data set has been widely used in similar studies (e.g. Cavazos, 2000; Cavazos et al., 2002; Hope et al., 2006) and is considered to be the best SLP data available for the study region and type of analysis (see Hope et al. (2006) for a detailed discussion). The NCEP/NCAR Reanalysis data is derived from a global spectral model with a grid resolution of 2.5 degree latitude $\times 2.5$ degree longitude global $(144 \times 73$ grids $)$.

\subsection{Rainfall data}

Historical instrumental daily rainfall data was obtained from the Australian Bureau of Meteorology for nine rainfall stations distributed across Victoria, Australia (see Fig. 1). The rainfall gauges were selected to represent nine target catchments that are important for water resources management in Victoria. Monthly rainfall totals from January 1948 to April 2006 were used in this study, with months containing more than 5 days of missing data excluded from the analysis.

\subsection{Climate indices}

\subsubsection{ENSO}

The Oceanic Niño Index (ONI) from the United States National Oceanic and Atmospheric Administration (NOAA) 


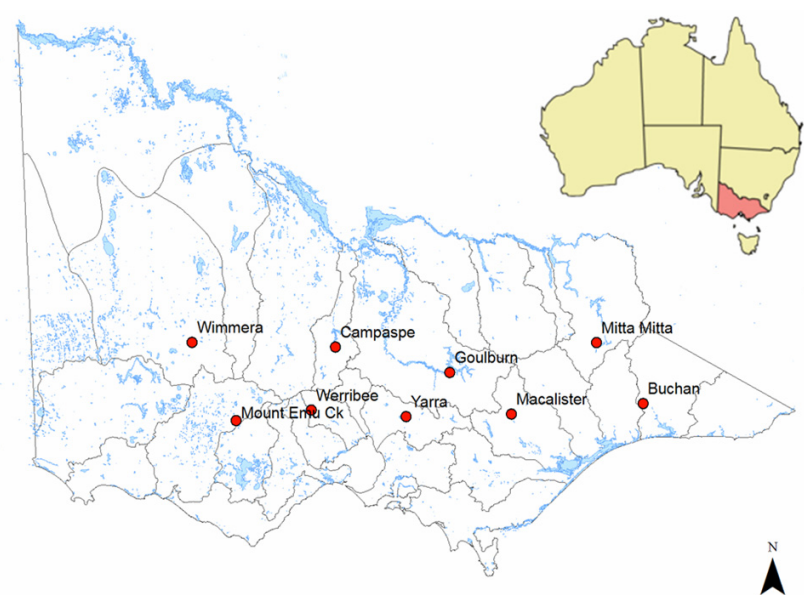

Fig. 1. Location of rainfall stations used in this study.

Climate Prediction Centre (CPC) is used to provide a representation of ENSO conditions. The ONI index is derived from sea surface temperature (SST) anomalies in the equatorial Pacific Ocean using a 3 month running mean of ERSST.v3 SST anomalies in the Niño 3.4 region $\left(5^{\circ} \mathrm{N}-5^{\circ} \mathrm{S}\right.$, $120^{\circ}-170^{\circ} \mathrm{W}$ ). Warm (positive) SST anomalies are associated with El Niño events, while La Niña events are typically associated with cold (negative) SST anomalies.

\subsubsection{IOD}

An index based on SST anomalies over Indonesia $\left(0-10^{\circ} \mathrm{S}\right.$, $\left.120-130^{\circ} \mathrm{E}\right)$ is used in this study to represent climate variability in the Indian Ocean associated with the Indian Ocean Dipole (IOD). This index, known as the Indonesian Index (II), relates to one of the "poles" of the Indian Ocean Dipole as identified by Nicholls (1989) and has been shown to be a good indication of winter rainfall in eastern Australia (Verdon and Franks, 2005). In fact, this index was found to relate better to east Australian rainfall than other IOD indices such as the Dipole Mode Index (DMI) of Saji et al. (1999). When SSTs are anomalously cool over Indonesia, winter rainfall tends to be lower, while warm SSTs in the same region are related to higher winter rainfalls in eastern Australia.

\subsubsection{SAM}

The SAM is represented by the monthly mean Antarctic Oscillation (AAO) index, available from NOAA CPC from 1979 to present and from Thompson and Wallace (2000) from 1948-2002. In this study the NOAA CPC version of the AAO is used where it exists (i.e. from 1979) and the Thompson and Wallace (2000) AAO data is used prior to that. Overlapping periods of the two versions of the AAO were compared and the difference was found to be negligible $\left(R^{2}=0.95\right)$. The AAO index is constructed by projecting the daily $700 \mathrm{mb}$ height anomalies poleward of $20^{\circ} \mathrm{S}$ onto the loading pattern of the AAO. The loading pattern of the AAO is defined as the leading mode of Empirical Orthogonal Function (EOF) analysis of monthly mean $700 \mathrm{hPa}$ height during 1979-2000 period.

\subsubsection{IPO}

Folland et al. (1999) derived an index of IPO variability using a low pass filter of near-global SSTs, while Power et al. (1999) applied a spectral filter with a 13 year cut-off to the raw IPO to generate a smoothed (or slowly varying) IPO timeseries. The smoothed timeries of Power et al. (1999) is used in this study in order to identify epochs of positive and negative IPO.

\section{Synoptic typing methodology}

The SOM methodology (Kohonen, 1995) is adopted to identify the key regional synoptic patterns driving rainfall variability in Victoria. SOM is a non-linear neural network classification technique developed to recognise relevant structures in complex, high-dimensional data via an unsupervised learning and self adaptation process (Cavazos et al., 2002). SOMs have been described as less complex, more robust and less subjective than more traditional techniques, including cluster analysis and principal component analysis, which are commonly used to identify synoptic patterns (Hewitson and Crane, 2002).

SOMs are essentially a mapping of many vectors onto a two dimensional array of representative nodes (in this case synoptic types) via an unsupervised learning algorithm. The first stage of the SOM is to initialise a specified number of reference vectors. The user defines the number of reference vectors to train the SOM (i.e. the size of the SOM array), which in this application corresponds to the number of synoptic types. An iterative approach is then used to train the SOM, according to the following process:

1. A sample vector from the input data set is chosen at random and the best matching node (reference vector) is determined by calculating the minimum Euclidean distance for each of the reference vectors;

2. Once the best matching node is identified for the input vector, the node and those close to it are updated towards the input vector;

3. Training continues using multiple iterations, until sTable values are reached (i.e. no further adjustment is made to the reference vector);

4. The analysis returns the types (or SOM states) in a grid or "map" with similar states located near each other and the most extreme states at the corners of the map; 


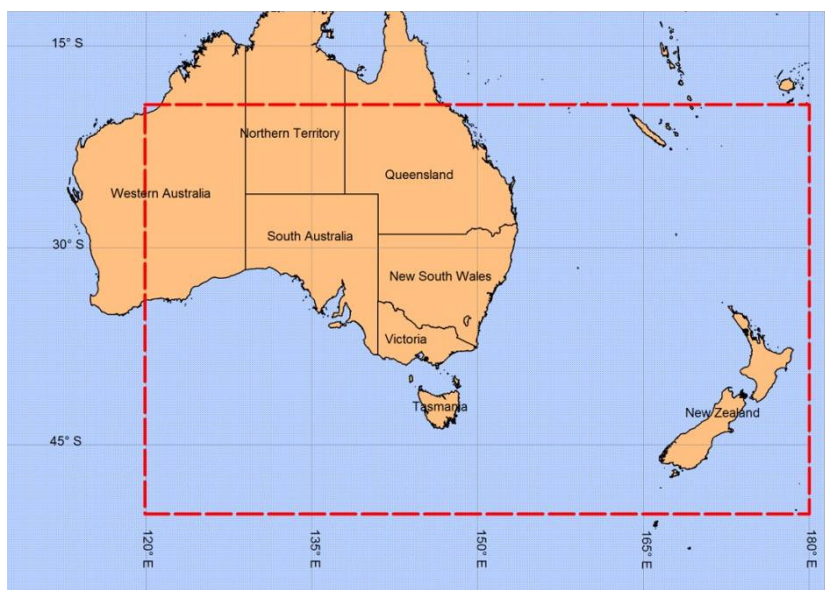

Fig. 2. Region over which the regional synoptic patterns are analysed in this study.

5. The input data is then classified by locating the best match to the final reference vector. In this case, monthly SLP patterns are matched to the archetypal patterns identified using the SOM to generate a timeseries of synoptic types.

In order to study the regional scale synoptic systems that are important for Victoria, a subset of the global SLP data was extracted to carry out the SOM. This region was chosen so as to capture the synoptic patterns that are known to deliver rainfall to Victoria, such as cut-off lows and frontal systems (following Pook et.al, 2006). The location of the SLP field used in this analysis $\left(120^{\circ} \mathrm{E}-180^{\circ} \mathrm{E}, 20^{\circ} \mathrm{S}-50^{\circ} \mathrm{S}\right)$ is shown in Fig. 2.

The size of the SOM array directly influences the range of synoptic patterns represented. A number of array sizes were trialled in order to determine the optimum number of synoptic patterns. It was determined that a 3 by 4 SOM (i.e. 12 types) was not large enough to adequately identify the subtle differences between types that are likely to be important in generating rainfall, however these subtleties were found to be captured by a 4 by 5 SOM (i.e. 20 types). Larger array sizes (e.g. a 5 by $6 \mathrm{SOM}$ ) resulted in further refinement of the transitionary synoptic types (resulting in very discrete differences between types) yet did not alter the extreme types. In addition, there was no improvement in the mean error per sample (calculated as the average Euclidian distance between the input vector and the synoptic types it best matches to) by increasing the size of the SOM array beyond 20 types. Given these findings a 4 by 5 SOM was chosen for the synoptic typing performed in this study - this array size satisfactorily captures a range of synoptic patterns with sufficient differences observed between types.

It is possible that the relationship between the regional synoptic patterns and the large-scale climate modes presented in this paper may be sensitive to the size of the SOM array and/or the resolution of the SLP data and/or the spatial region over which the SOM is applied. Therefore, it is acknowledged that further sensitivity analysis is required to determine if/how the relationships identified here change when SOM is applied to different SLP data sets and/or larger/smaller spatial regions than that identified in Fig. 2.

\section{Regional-scale climate variability in Victoria}

\subsection{Identification of 20 key regional synoptic patterns}

The synoptic typing was carried out using the freely available SOM software ("SOM Toolbox for Matlab 5", produced by the SOM Toolbox Team, Helsinki University of technology). Twenty synoptic types (using a 4 by 5 grid) were generated using the monthly SLP data, as shown in Fig. 3. By virtue of the method similar types are clustered together in the SOM, with the most dissimilar types located at the far corners of the SOM map.

Figure 3 demonstrates that the 20 synoptic types capture a range of significant synoptic features known to influence the weather of the region. These include the clear seasonal trend in the location and intensity of the semi-permanent $\mathrm{Pa}$ cific and Indian Ocean high pressure systems that are associated with the Sub-Tropical Ridge (STR). Variability in the strength and location of the east coast trough, located between the two semi permanent high pressure systems, is also evident (i.e. lower left corner of SOM map).

It would be expected that type $1 \mathrm{~A}$ and to a lesser extent type $1 \mathrm{~B}$ and $2 \mathrm{~B}$ would result in high rainfall for the south coast of Victoria. This is due to the northward movement of the high pressure systems and the presence of a pre-frontal trough, which would allow rain producing southern ocean cold fronts to penetrate into southern Victoria (Tapper and Hurry, 1996). While synoptic type 2A appears to be similar to $1 \mathrm{~A}$ in terms of the location of the high pressure systems, this pattern is unlikely to produce significant rainfall as the pre-fontal trough is located south of Victoria and is much weaker than the trough displayed in type 1A. The blocking high, located in the Southern Ocean for type 2A, is also likely to prevent cold fronts from passing through Victoria.

It is expected that high rainfall would be associated with synoptic type $5 \mathrm{~A}$ due to the extension of the east coast trough into Victoria. Stormy conditions often occur along this trough line during warmer months due to an enhancement of vertical motion just ahead of the trough, resulting in intense rainfall (Sturman and Tapper, 2004). The trough tends to move in an eastward direction and thus it is expected that rainfall in the northern western region would be influenced by this pattern to a greater degree than the southwestern region. While synoptic types 2A, 3A, 4A, 3B and 4B also display a similar east coast trough line, the trough only penetrates as far as New South Wales, with high pressure situated over Victoria (associated with the STR). Therefore, this 


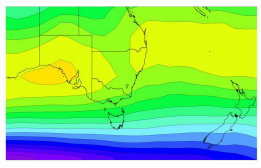

Synoptic Type 1A

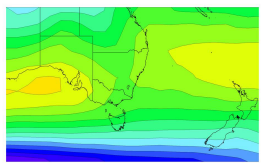

Synoptic Type 2A

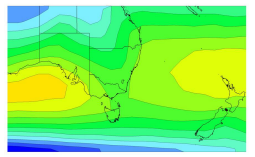

Synoptic Type 3A

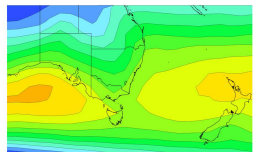

Synoptic Type 4A

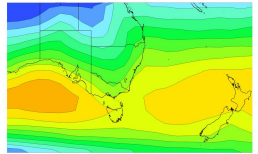

Synoptic Type 5A

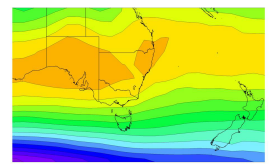

Synoptic Type 1B

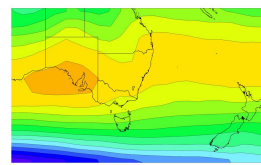

Synoptic Type 2B

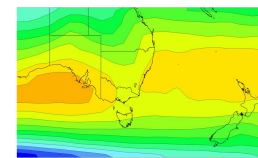

Synoptic Type 3B

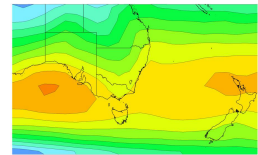

Synoptic Type 4B

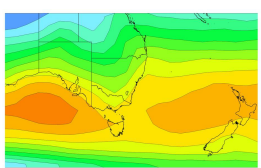

Synoptic Type 5B

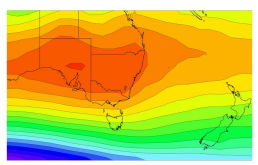

Synoptic Type 10

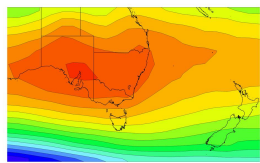

Synoptic Type 2C

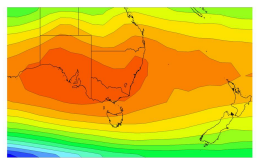

Synoptic Type 3C

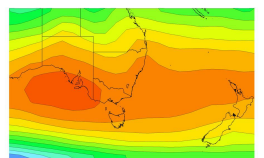

Synoptic Type 4C

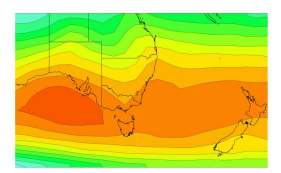

Synoptic Type 5C

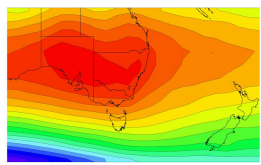

Synoptic Type 1D

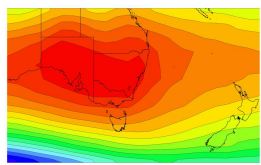

Synoptic Type 2D

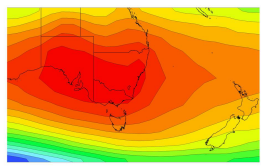

Synoptic Type 3D

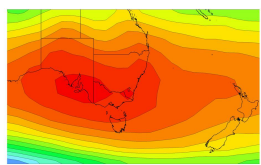

Synoptic Type 4D

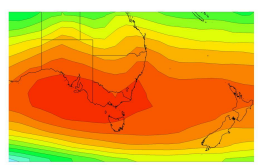

Synoptic Type 5D

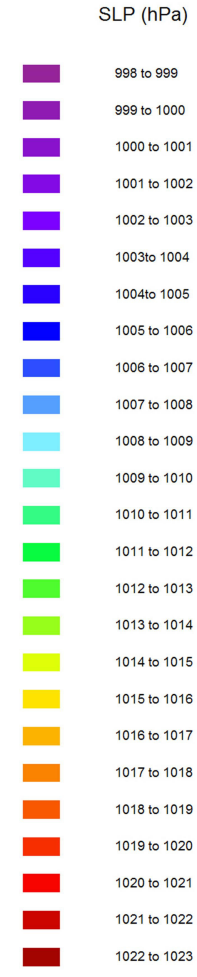

Fig. 3. 20 key regional synoptic patterns characterised using SOM. situation is more likely to result in clear (i.e. dry) weather for that region.

Synoptic type 4C exhibits a low pressure trough located offshore, running parallel to the coast, also known as an 'easterly dip' (Sturman and Tapper, 2004). The offshore trough is often associated with the development of particularly heavy rainfall along the east coast of Australia. Some offshore easterly dips can lead to the development of east coast cyclones (i.e. cut off lows/Tasman lows) during cooler months which are associated with intense rainfall events in Victoria and NSW. Synoptic types 3D and 4D display divergence in the isobars located in the Pacific Ocean, east of NSW, which may lead to the development of east coast lows. However, these are unlikely to result in significant rainfall for Victoria as their development is too far to the north.

\subsection{Seasonality of the 20 key synoptic types}

A time-series of synoptic patterns was generated by classifying the monthly SLP values (from January 1948 through to April 2007) according to the 20 synoptic types. The classification was achieved by calculating the best matching unit for each month. Figure 4 shows the distribution of synoptic types within each season for the study period (January 1948 to April 2007).
Clear seasonality in the synoptic types is evident in Fig. 4, particularly during the summer and winter months. Winter types tend to be mapped to the top right of the SOM, while summer types tend to map to the bottom left of the SOM. Common winter types (e.g. 1B, 1C, 1D, 2C, 2D, 3D, 4D) are associated with northward movement of the STR and the linking of the Pacific and Indian Ocean high pressure systems. The most common summer types (e.g. 2A, 3A, 4A, $4 \mathrm{~B}, 5 \mathrm{~A}, 5 \mathrm{~B}, 5 \mathrm{C})$ are associated with southward movement of the semi permanent high pressure systems (Pacific and Indian Ocean high associated with the STR) and a deepening of the east coast low pressure trough.

\subsection{Rainfall associated with each of the 20 synoptic types}

Rainfall distributions associated with each of the 20 synoptic types were calculated using the monthly rainfall data described in Sect. 2.2. The rainfall distributions are illustrated in Figure 5.

From Fig. 5 it is clear that rainfall distributions vary markedly for different synoptic types at the same site (and for the same synoptic type across the different sites). Typically, "wet" types tend to be associated with synoptic patterns that map to the top two rows of the SOM (i.e. 1A through to 2D), 


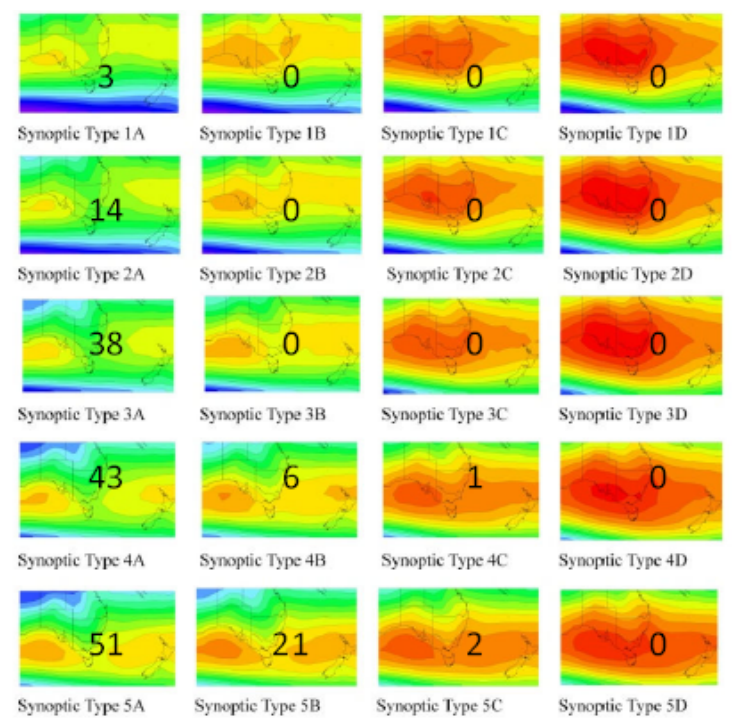

Summer

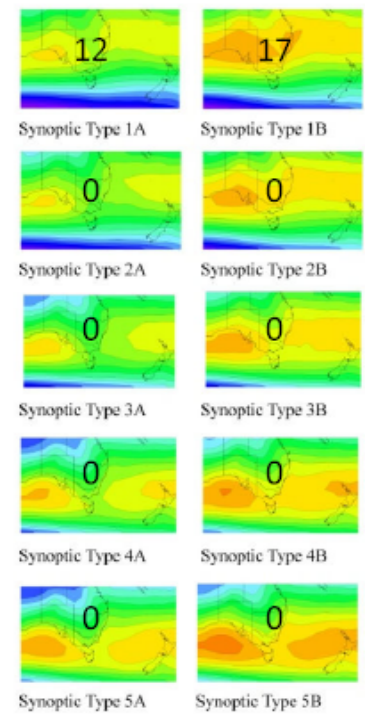

Winter

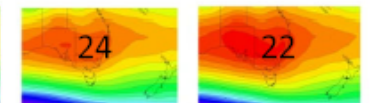

Synoptic Type IC Synoptic Type ID
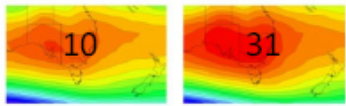

Synoptic Type 2D
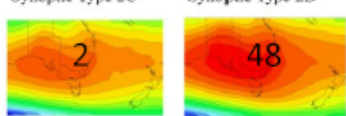

Synoptic Type 3D

Synoptic Type 3C

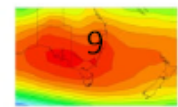

Synoptic Type 4D

Synoptic Type 4C

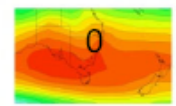

Synoptic Type 5D
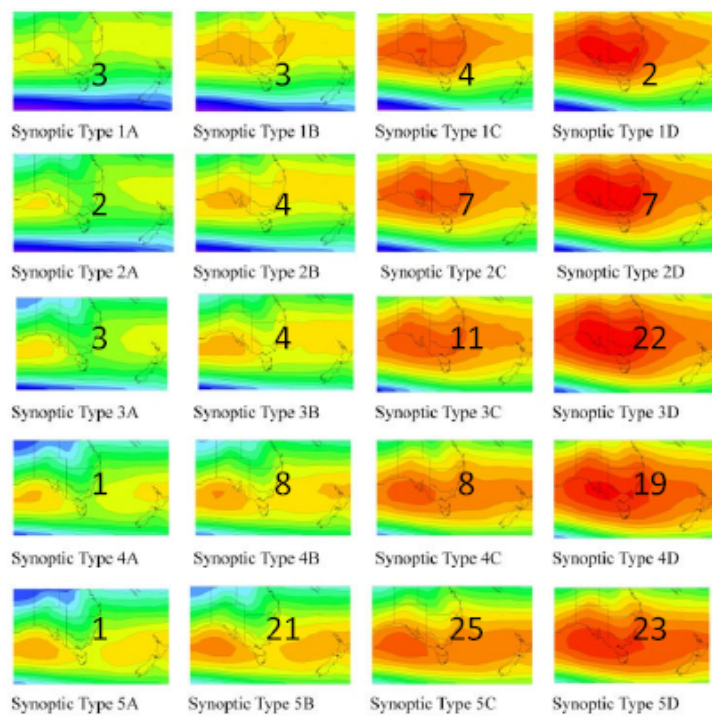

Synoptic Type ID

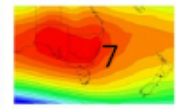

Synoptic Type 2C

Synoptic Type 2D
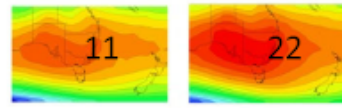

Synoptic Type 3C

Synoptic Type 3D
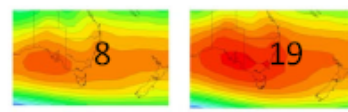

Synoptic Type 4C

Synoptic Type 4D
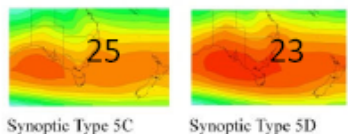

Autumn
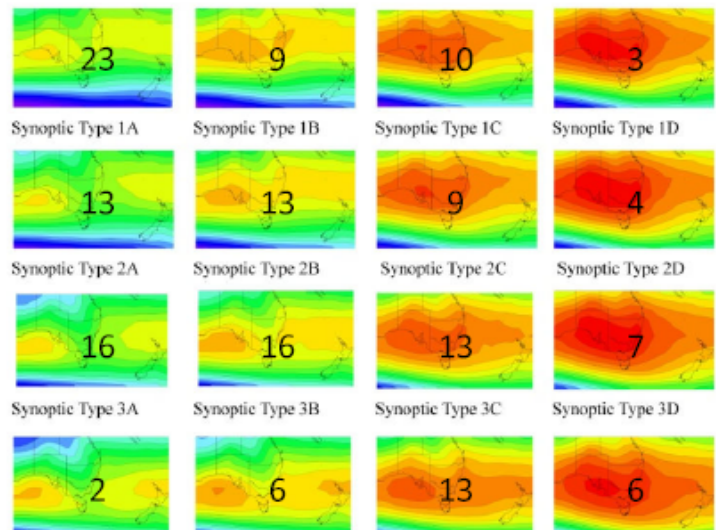

Synoptic Type 1C

Synoptic Type ID

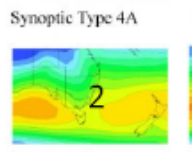

Synoptic Type 5A
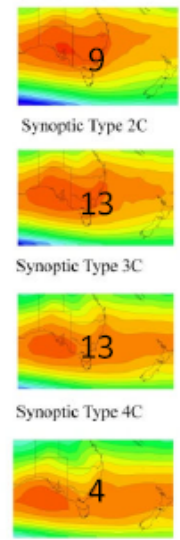

Synoptic Type 5C

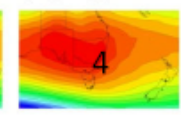

Synoptic Type 2D

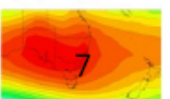

Synoptic Type 3D

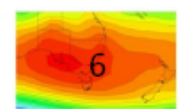

Synoptic Type 4D

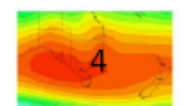

Synoptic Type 5D

\section{Spring}

Fig. 4. Number of times each synoptic type has occurred since 1948 on a seasonal basis. Note: Fig. 3 features a magnified version of the SOM matrix under laying the frequency of occurrence numbers shown here.

while "dry" types tend to be associated with synoptic patterns that map to the bottom two rows of the SOM (i.e. 4A to 5D), with a few noTable exceptions (including the "wet" 4C and 5A types). Generally, the highest rainfall is associated with type $1 \mathrm{~A}$, representing a strong pre-frontal trough, with rainfall generated out of the southern Ocean. This result is consistent at all stations except the two far eastern stations, Buchan and Mitta Mitta, where synoptic types 3A (weak east coast trough) and $4 \mathrm{C}$ (easterly dip) tend to deliver equally high rainfalls. While type $3 \mathrm{~A}$ tends to result in high rainfall in eastern Victoria, this system is generally associated with below average rainfall for the south western stations, which is most likely a result of the blocking high pressure system located over south west Victoria and the eastward movement of the low pressure trough. Type $5 \mathrm{~A}$ is also reasonably wet for the far eastern stations, which is related to the extension of the east coast trough into Victoria. High rainfall tends to be associated with type $4 \mathrm{C}$ across all regions, as expected, due to the representation of an "easterly dip". The spatial variability of the rainfall associated with each synoptic type, and the physical mechanisms behind this, is further discussed in Kiem and Verdon-Kidd (2009). 

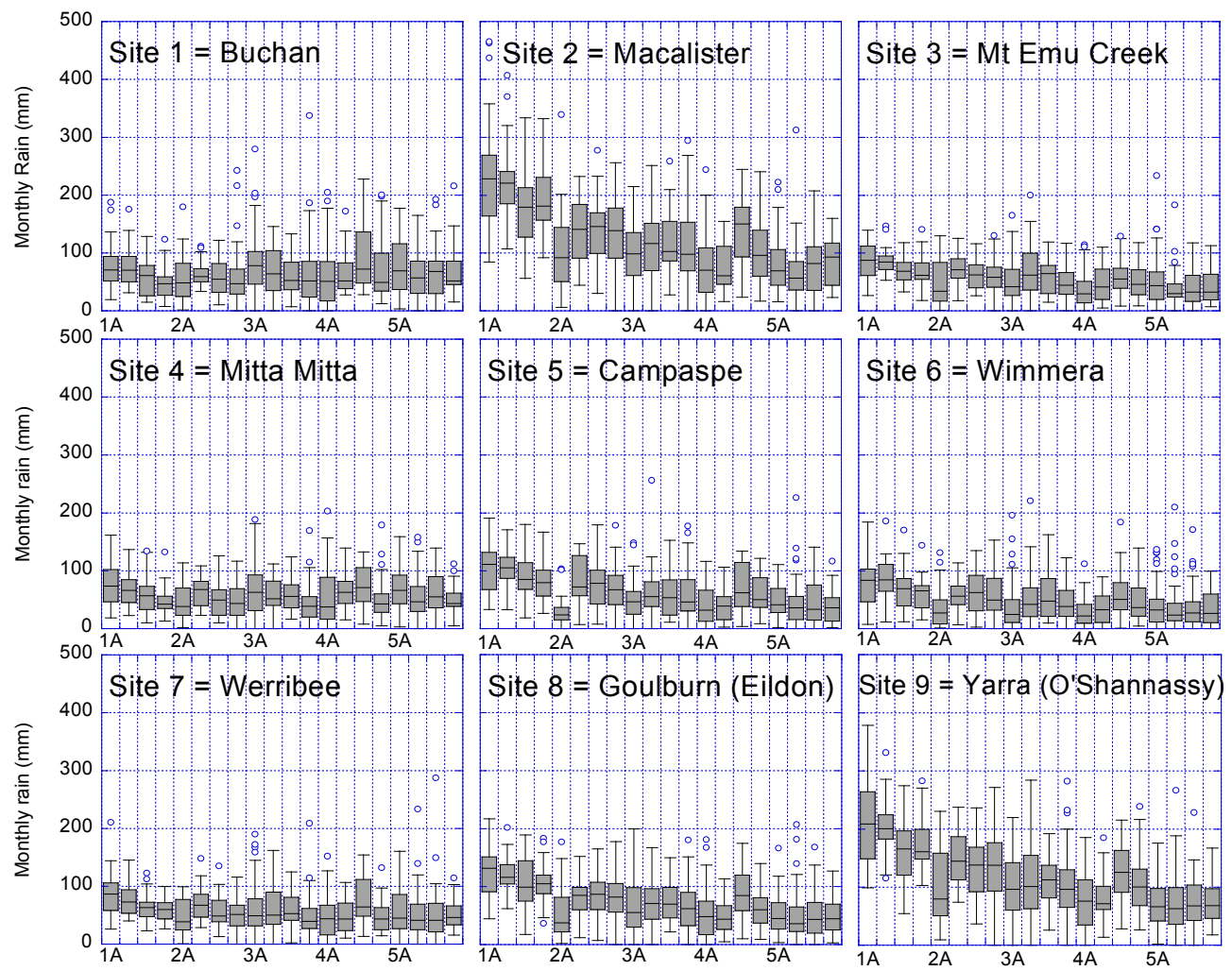

Fig. 5. Box plots of monthly rainfall associated with each of the 20 synoptic types. Horizontal line within the box indicates the median. Dots indicate observations that are considered statistical outliers (i.e. extreme events that are greater than 1.5 times the width of the box, which is the difference between the 75 th percentile and the 25 th percentile of the distribution).

\subsection{Relationship with large-scale climate drivers - inter-annual variability}

As discussed previously, a number of large-scale climate modes (i.e. ENSO, IOD and SAM) are known to influence the climate of Victoria on an annual to inter-annual timescale. Table 1 shows the average index value of the large-scale climate modes associated with each synoptic type (refer to Section 2.3 for further information on the ENSO, IOD and SAM indices used in this study).

From the analysis shown in Table 1 it is clear that the certain synoptic types (and therefore weather conditions) are more likely in particular phases of the large-scale climate modes. For example, when the tropical Pacific Ocean is in a La Niña like state (i.e. negative ONI) synoptic patterns 1A, $4 \mathrm{~A}$ and $5 \mathrm{~A}$ are most likely $-1 \mathrm{~A}$ and $5 \mathrm{~A}$ (and to a lesser degree 4A) are associated with high rainfall in Victoria, particularly for the eastern stations. Conversely, strongly positive ONI conditions (i.e. El Niño) tend to be associated with types 3B, 3D and 4B which in turn are associated with average/below average rainfall across Victoria. There is also a clear relationship between the SAM and the regional synoptic patterns, with negative SAM linked to synoptic types located at the top left of the SOM (i.e. wet types) and positive
SAM linked to those types located at the bottom right (i.e. dry types). It is also interesting to note that synoptic type 1A, associated with the highest rainfall across Victoria, tends to occur when the Pacific Ocean is in a La Niña state, the SAM is negative and warm SSTs dominate the East Indian Ocean. That is, the greatest rainfall is likely to be experienced in Victoria when all three climate modes simultaneously occur in their "wet phase".

Table 1 also demonstrates the complexity involved in determining when and where each large-scale climate mode impacts Victorian rainfall. For example, it is shown that when the ONI is negative (i.e. La Niña) types $1 \mathrm{~A}, 4 \mathrm{~A}$, and $5 \mathrm{~A}$, which are all "wet" types, are more likely. However, type $5 \mathrm{~B}$ (a "dry" type) is also possible when ONI is negative and other "wet" types (e.g. 2A, 3A, 4C) are not associated with a negative ONI. Therefore, all "wet" events are not associated with La Niña conditions and, conversely, all La Niña events are not associated with "wet" events (and vice versa for El Niño and "dry" conditions). These results demonstrate why direct relationships between ENSO and Victorian rainfall (and streamflow) tend to be weaker than other parts of eastern Australia (e.g. Chiew et al., 1998; Verdon et al., 2004). Similarly a direct correlation between SAM and rainfall in Victoria would result in mixed relationships (e.g. Kiem 
Table 1. Average monthly index value (ENSO, IOD, and SAM) associated with the 20 key regional synoptic types for Victoria.

\begin{tabular}{crrr}
\hline $\begin{array}{c}\text { Synoptic } \\
\text { Type }\end{array}$ & $\begin{array}{r}\text { Average } \\
\text { ENSO (ONI) }\end{array}$ & $\begin{array}{r}\text { Average } \\
\text { IOD (II) }\end{array}$ & $\begin{array}{r}\text { Average } \\
\text { SAM (AAO) }\end{array}$ \\
\hline 1A & -0.13 & 0.24 & -0.91 \\
1B & 0.10 & 0.10 & -0.64 \\
1C & 0.15 & 0.08 & -0.62 \\
1D & 0.22 & -0.04 & 0.19 \\
2A & 0.16 & 0.26 & -0.82 \\
2B & 0.19 & 0.03 & -0.21 \\
2C & 0.20 & 0.01 & -0.38 \\
2D & 0.25 & -0.10 & 0.70 \\
3A & 0.01 & 0.25 & -0.33 \\
3B & 0.43 & 0.16 & -0.18 \\
3C & 0.02 & 0.20 & 0.26 \\
3D & 0.30 & -0.13 & 0.45 \\
4A & -0.17 & 0.20 & 0.94 \\
4B & 0.28 & 0.36 & 0.44 \\
4C & 0.22 & 0.22 & 0.17 \\
4D & 0.19 & 0.07 & 0.50 \\
5A & -0.25 & 0.28 & 0.11 \\
5B & -0.08 & 0.27 & 0.39 \\
5C & 0.09 & 0.33 & 0.36 \\
5D & 0.00 & 0.21 & 0.34 \\
\hline
\end{tabular}

and Verdon-Kidd, 2009). For example, both types 1A and 2A are associated with strongly negative SAM, however rainfall for type $1 \mathrm{~A}$ tends to be much greater. This demonstrates that interactions between large-scale climate drivers and regional synoptic patterns must be understood and accounted for in order to better understand (and predict) variability in Victoria's climate.

To further investigate the relationship between the regional synoptic patterns and the large-scale climate modes the occurrence of each of the 20 regional synoptic patterns were stratified based on the state of the individual modes. Each month from January 1948 to April 2006 was classified as El Niño, La Niña or Neutral based on ONI and the NOAA ENSO classification definition. The same classification procedure was used to classify months as IOD positive, negative or neutral (using the II) and SAM positive, negative, or neutral (using the AAO). The number of times each synoptic pattern occurred in combination with an El Niño, La Niña or Neutral event is shown in Fig. 6. Similarly Fig. 7 displays the results for IOD and Figure 8 shows the relationship for SAM.

There is a clear trend towards a higher frequency of synoptic types $4 \mathrm{~A}$ and $5 \mathrm{~A}$ occurring in combination with a La Niña event (as opposed to El Niño) during the summer months. As discussed previously these synoptic patterns are associated with high rainfall for the two eastern stations (i.e. Buchan and Mitta Mitta). Figure 6 also shows that synoptic type 1A (a very wet type) only occurs in autumn in combination with a La Niña event, indicating that the autumn break (which plays an important role in resulting winter runoff) may be more reliable in a La Niña year. Furthermore, there is an apparent trend towards more of type 3D in winter of an El Niño, which tends to be associated with fairly dry conditions across Victoria.

The IOD is thought to impact rainfall in Australia primarily in winter and spring, when the dipole itself is most active (Verdon and Franks, 2005). This also appears to be the case for the regional synoptic patterns, as shown in Figure 7. For example, during these seasons, there is a clear trend towards more frequent wet types (e.g. 1A, 1B and 1C), and an associated decrease in dry type 3D, when the waters around Indonesia are anomalously warm (resulting in a negative dipole).

Across all seasons there is a trend in the relationship between the SAM and the regional synoptic patterns (shown in Fig. 8). That is, the negative phase of the SAM appears to favour the occurrence of synoptic types located at the top left of the SOM (which are generally wet types), while the positive phase tends to be connected to the occurrence of synoptic patterns located on the bottom right of the SOM (which generally correspond to dry types). This difference is most apparent in the spring and autumn seasons.

\subsection{Relationship with large-scale climate drivers - multi-decadal variability}

As discussed in the Introduction, the climate of eastern Australia has experienced a number of multi-decadal shifts (i.e. mid 1940's and mid 1970's) in climate which have since been associated with the IPO/PDO. In order to investigate if these multi-decadal shifts have resulted in changes in the regional synoptic patterns, the frequency of types post 1978 (i.e. positive IPO) were compared to the frequency of types during the period 1948-1978 (i.e. IPO negative). The results are shown in Fig. 9.

Figure 9 demonstrates that there are distinct differences in the synoptic patterns between the two climatic periods defined by the IPO. This is most evident in autumn, where the positive phase of the IPO is associated with a decreased frequency of wet types (e.g. 1A,1B and 2A) and an increased frequency of dry types (e.g. 3D, 4D, 5D). In fact, Fig. 9b shows that the extreme wet types (e.g. 1A and 1B) have been completely absent in autumn during the recent IPO positive phase (i.e. post 1978). This result is consistent with the drying trend observed in Victoria during autumn over the past 15 years (Murphy and Timbal, 2007; Kiem and Verdon-Kidd 2009, and the references therein). Further analysis into the climatic drivers (both large-scale and regional) of the "1997 step change" is currently underway. 

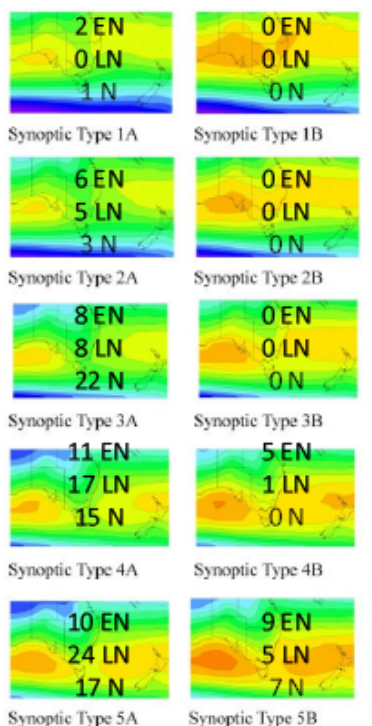

Synoptic Type 4B

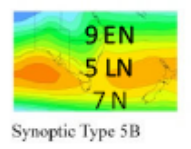

\section{Summer}
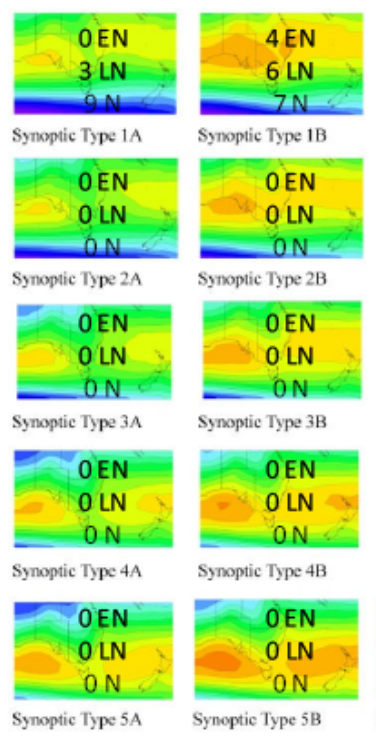

Winter

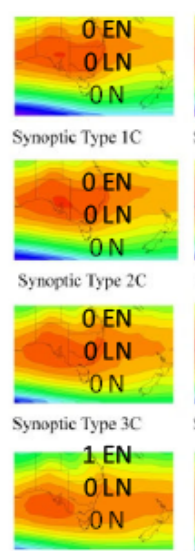

Synoptic Type 4C

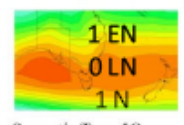

Synoptic Type 5C

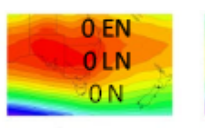

Synoptic Type ID

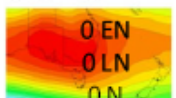

Synoptic Type 2D

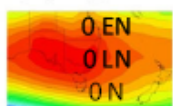

Synoptic Type 3D

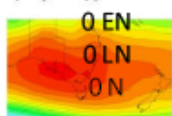

Synoptic Type 4D

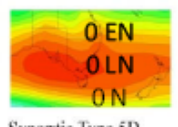

Synoptic Type 5D

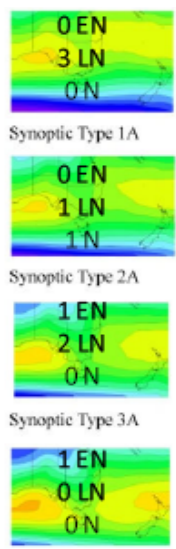

Synoptic Type 4A

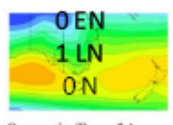

Synoptic Type 5A

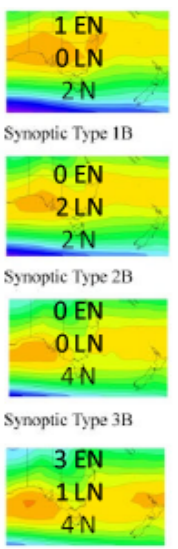

Synoptic Type 4B

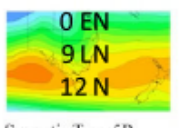

Synoptic Type 5B
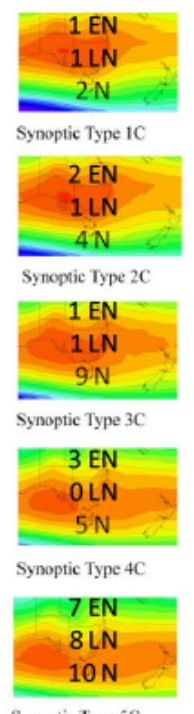

Synoptic Type 5C

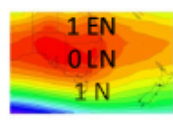

Synoptic Type ID

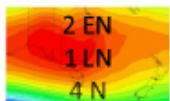

Synoptic Type 2D

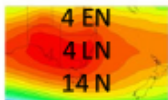

Synoptic Type 3D

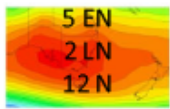

Synoptic Type 4D

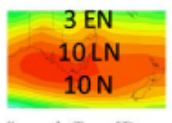

Synoptic Type 5D

Autumn
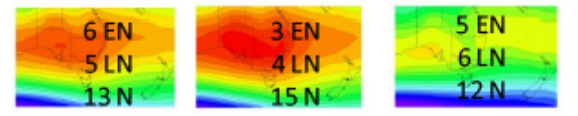

Synoptic Type 1A

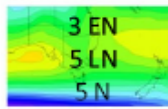

Synoptic Type 2A

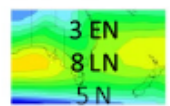

Synoptic Type 3A

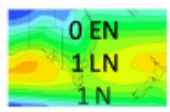

Synoptic Type 4A

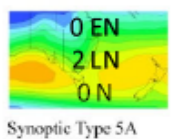

Spring
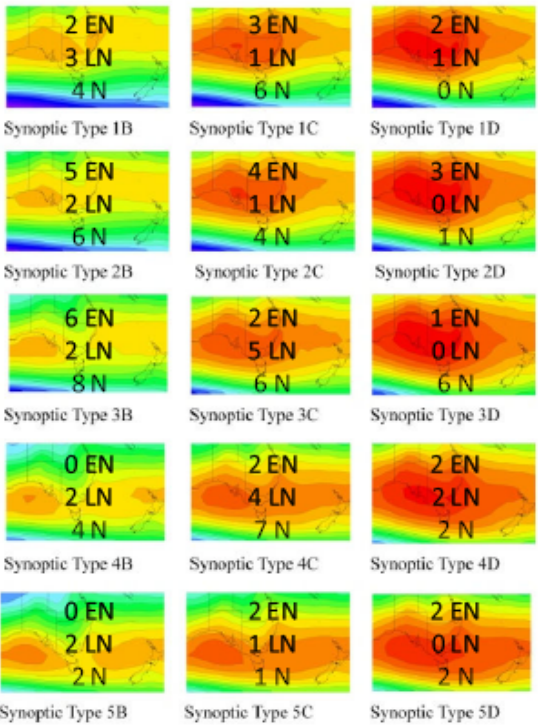

Synoptic Type ID
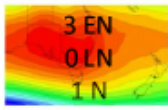

Synoptic Type 2D

Synoptic Type 2C
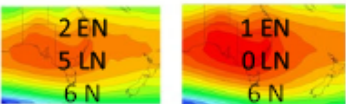

Synoptic Type 3C

Synoptic Type 3D
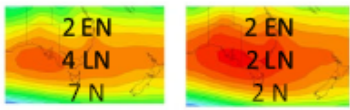

Synoptic Type $4 \mathrm{C}$

Synoptic Type 4D
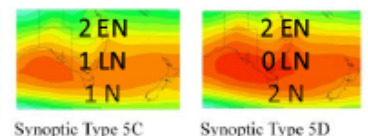

Fig. 6. Number of times each synoptic type has occurred since 1948 on a seasonal basis, stratified into El Niño (EN), La Niña (LN) and Neutral (N) phases. Note: Fig. 3 features a magnified version of the SOM matrix under laying the frequency of occurrence numbers shown here.

\section{Conclusions}

It is clear that Pacific, Indian and Southern Ocean climate variability plays an important role in modulating the regional synoptic systems that deliver rainfall to Victoria. It is also shown that the dominance of the large-scale climate modes (e.g. ENSO, IOD and SAM) varies with season and the resulting impact differs in strength from location to location.

The analysis presented here has marked implications in a variety of climate impact related areas, in particular seasonal forecasting of rainfall and streamflow in Victoria. To date the upper limit of seasonal predictability for southeast Australia is estimated at only $30 \%$ (based on a summary of the reports and results produced through the South East Australian Climate Initiative (SEACI, http://www.mdbc.gov.au/subs/seaci/ index.html). In comparison, seasonal forecasting schemes applied in other regions of Australia, such as Queensland, have proven very successful. This is likely due to the complex interactions between the numerous climatic phenomena (both regional and global-scale) that influence Victoria's 

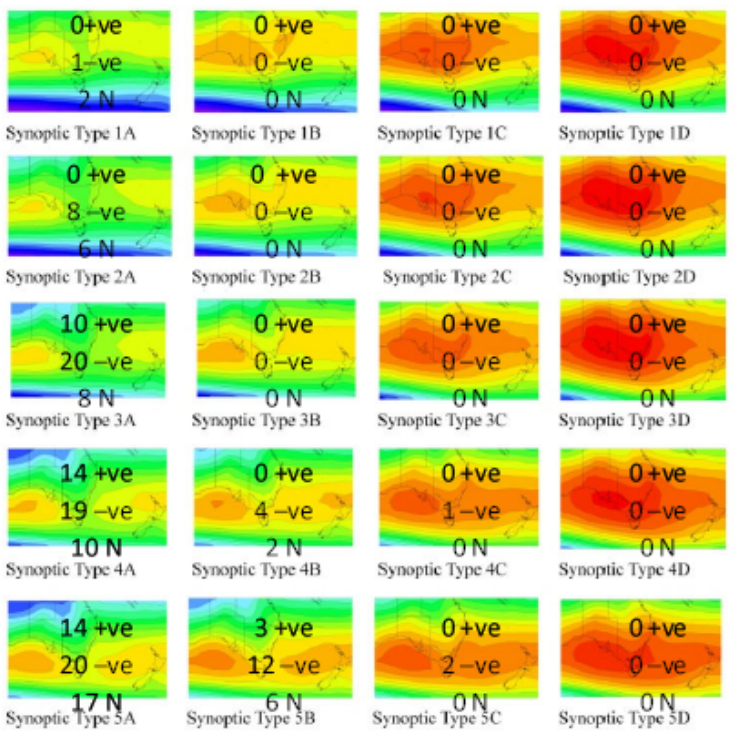

Synoptic Type 1B

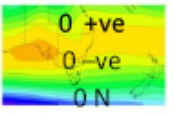

Synoptic Type 2B

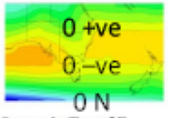

Synoptic Type 3B
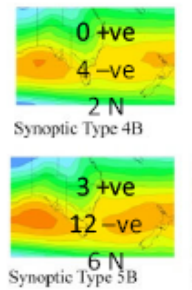

Synoptic Type 1C

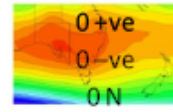

Synoptic Type 2C

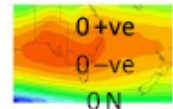

Synoptic Type 3C
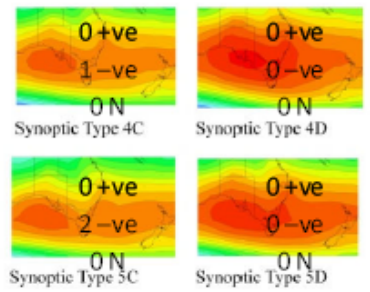

\section{Summer}
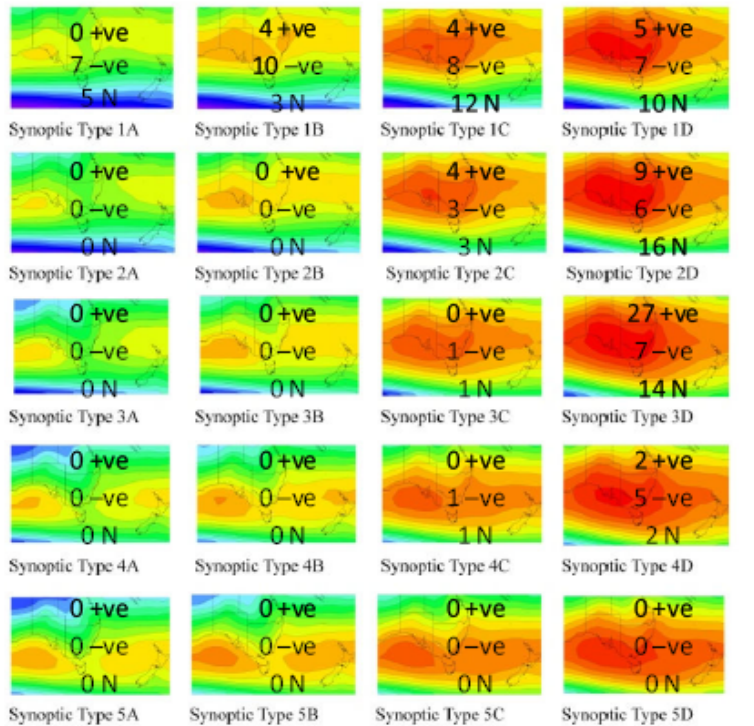

Synoptic Type 2C

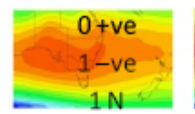

Synoptic Type 3C

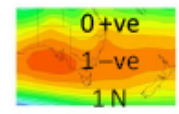

Synoptic Type 4C

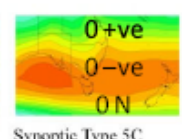

Synoptic Type 5C

\section{Winter}

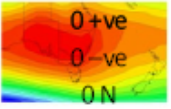

Synoptic Type 2D

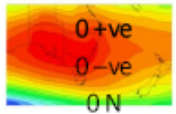

Synoptic Type 3D

Synoptic Type 2D

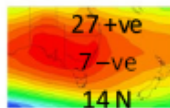

Synoptic Type 3D

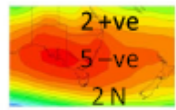

Synoptic Type 4D

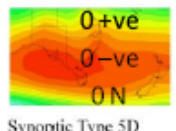

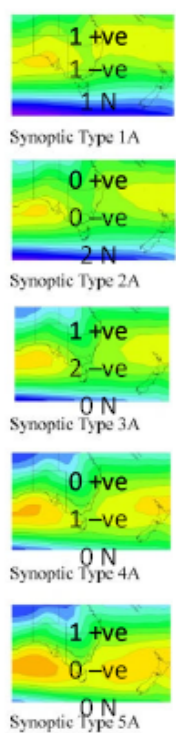
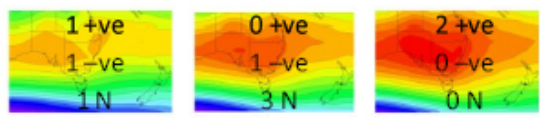

Symopic Type 1B

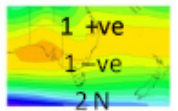

Synoptic Type IC

Synoptic Type ID

\section{Autumn}

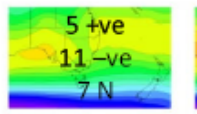

Synoptic Type $1 \mathrm{~A}$

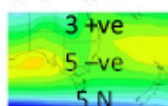

Synoptic Type $2 A$

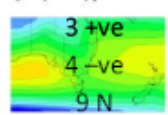

Synoptic Type $3 \mathrm{~A}$

Synoptic Type 2B

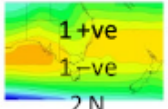

Synoptic Type 3B
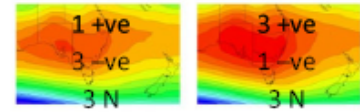

Synoptic Type $2 \mathrm{C}$

Synoptic Type 2D
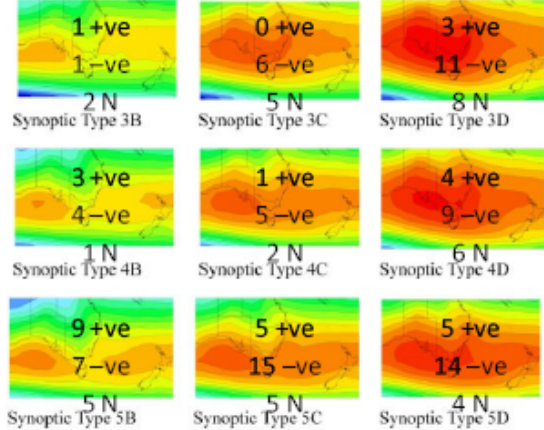

Synoptic Type $3 \mathrm{C}$

Synoptic Type 3D
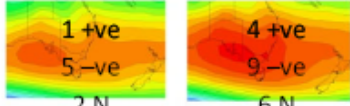

Synoptic Type $4 \mathrm{C}$

Synoptic Type 4D
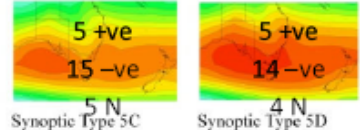

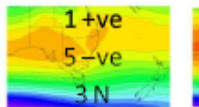

Synoptic Type 1B

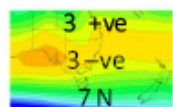

$\frac{7 \mathrm{~N}}{\text { Synoptic Type 2B }}$

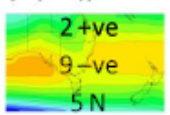

$5 \mathrm{~N}$
Synoptic Type 3B

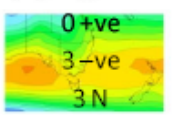

Synoptic Type 4B
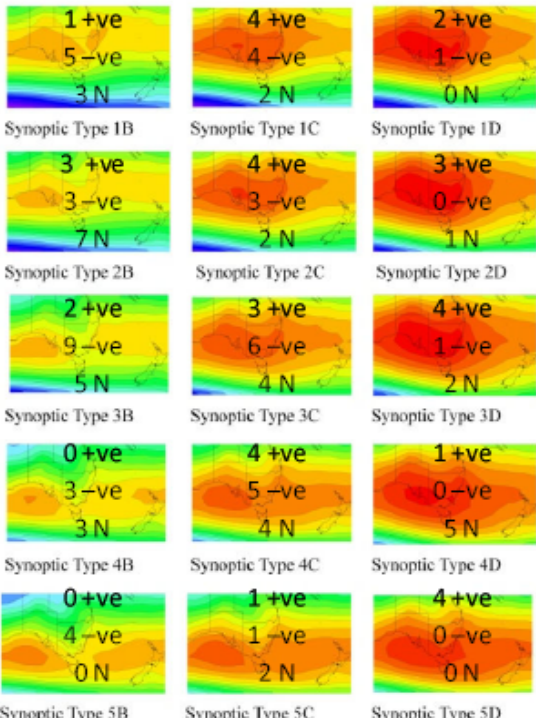

Synoptic Type $1 \mathrm{C}$

Synoptic Type ID

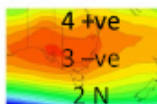

$3+v e$

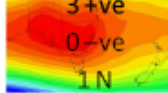

Synoptic Type $2 \mathrm{C}$

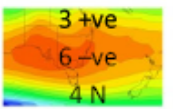

Synoptic Type 2D

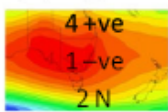

Synoptic Type 3C

Synoptic Type 3D
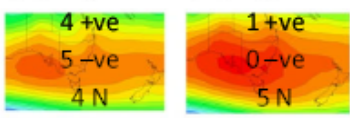

Synoptic Type 4C

Synoptic Type 4D

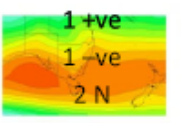

Synoptic Type 5C

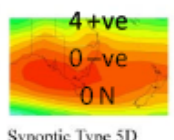

Synoptic Type 5D

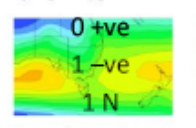

Synoptic Type 4A

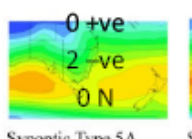

Spring

Fig. 7. Number of times each synoptic type has occurred since 1948 on a seasonal basis, stratified into IOD positive (+ve), IOD negative $(-\mathrm{ve})$ and IOD neutral $(\mathrm{N})$ phases. Note: Fig. 3 features a magnified version of the SOM matrix under laying the frequency of occurrence numbers shown here.

weather and the fact that this is not adequately represented in current forecasting schemes (either dynamical models or statistically based) - most likely because the characteristics and interactions associated with the large-scale and regional climate drivers are not yet fully understood.

The results presented in this study demonstrate that any seasonal forecasting framework (dynamical model or statistically based) should take into account interactions between all climate phenomena known to affect the predictand. Forecasting schemes based on large-scale climate indices (e.g.
SOI, Niño 3.4 etc.) are a simplification of this given that a climate index only covers a small region assumed to represent an entire climate mode (and all its variations). However, there is no such thing as a typical climate event - some climate events are similar but in reality it is rare that climatic episodes evolve in the same manner. This natural variation is difficult to reflect using large-scale climate indices and therefore forecasts based on indices that are not regionally specific will always lead to a 'coarse' or 'generalised' result. It is for this reason that this study sought to identify the re- 

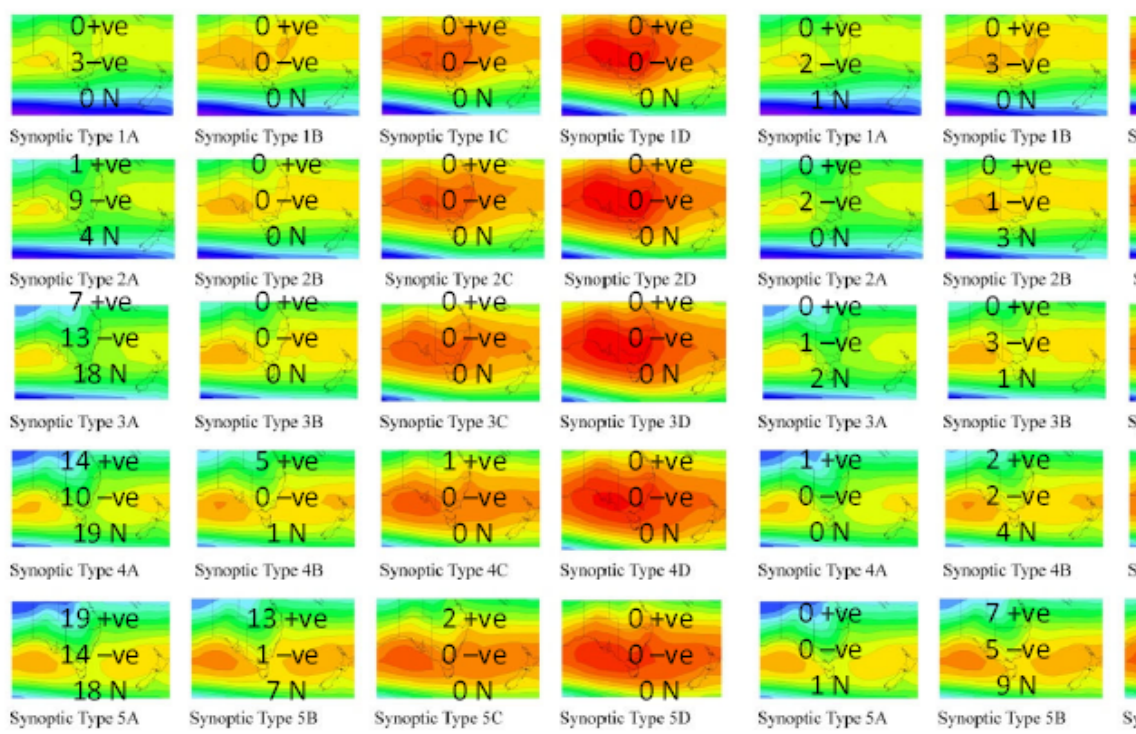

Synoptic Type 3B

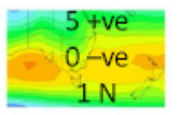

Synoptic Type 4B

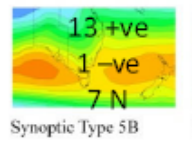

\section{Summer}
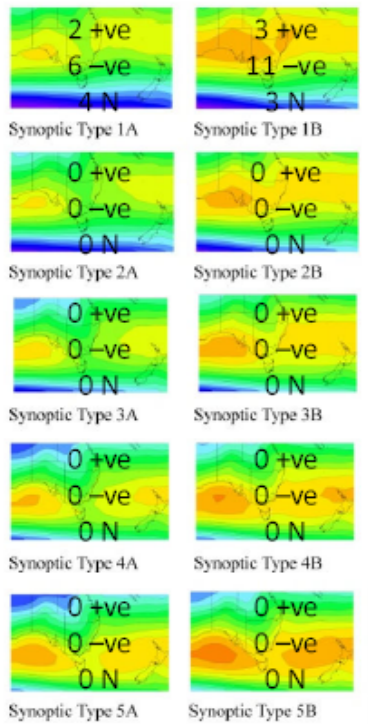

\section{Winter}

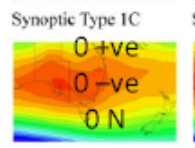

Synoptic Type ID

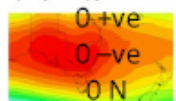

Synoptic Type 2C
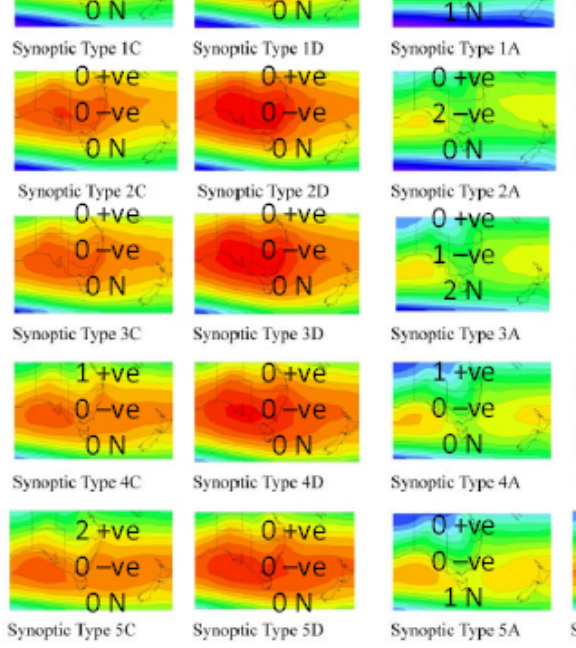

Synoptic Type 2D

Synoptic Type 3C

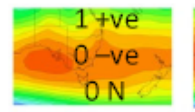

Synoptic Type 4C
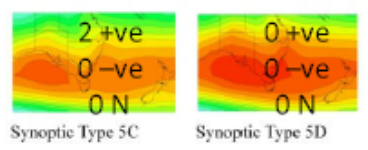

\section{Autumn}

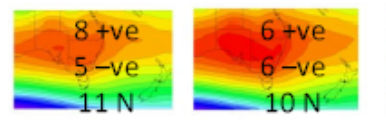

Synoptic Type 1C Synoptic Type ID
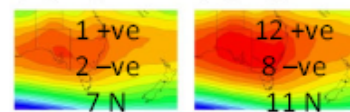

$-11 \mathrm{~N}$

Synoptic Type 2D

Synoptic Type $2 \mathrm{C}$

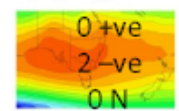

$-\mathrm{ON}$
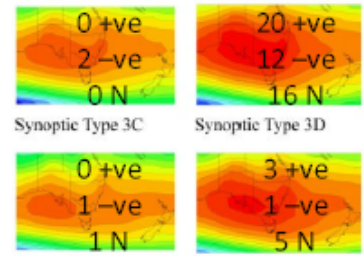

Synoptic Type 4C

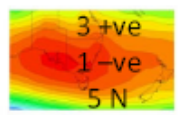

Synoptic Type 4D

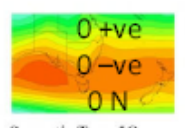

Synoptic Type 5C

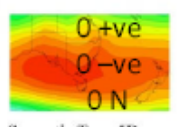

Synoptic Type 5D
Synoptic Type 3D
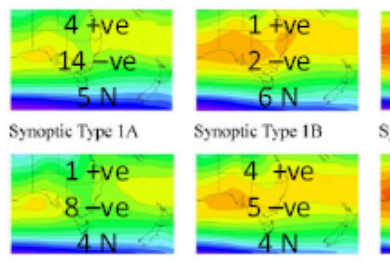

Synoptic Type 2B

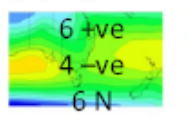

Synoptic Type 3A

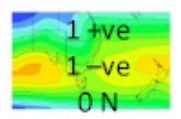

Synoptic Type 4A

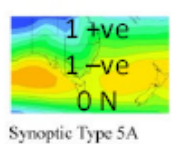

Spring

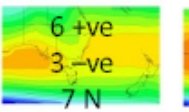

Synoptic Type 3B

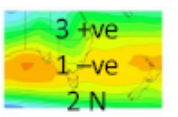

Synoptic Type 4B

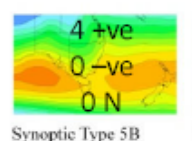

Synoptic Type 1B
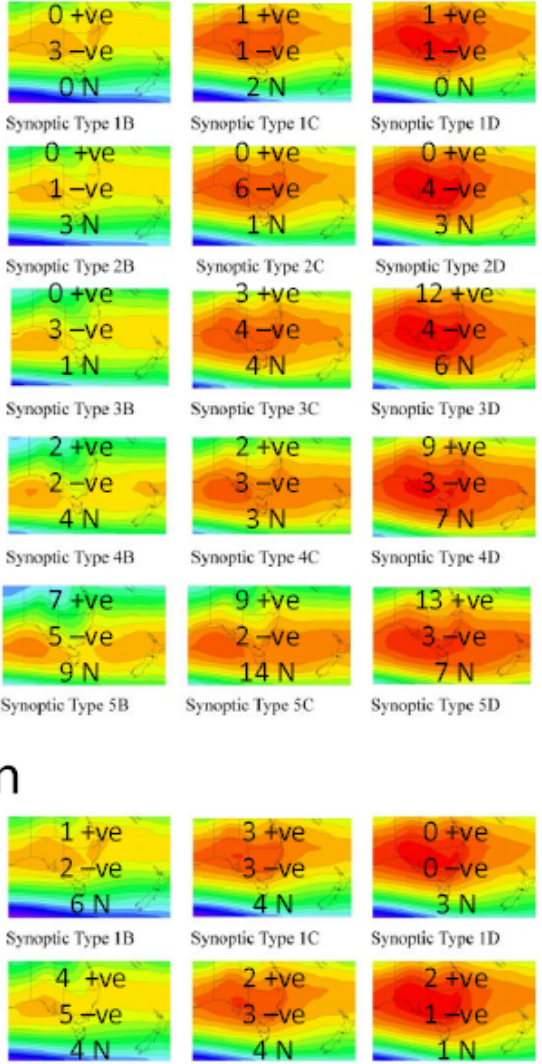

Synoptic Type 1D

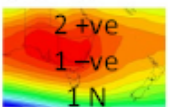

Synoptic Type $2 \mathrm{D}$

Synoptic Type $2 C$
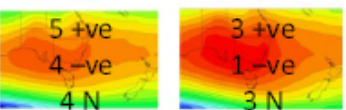

Synoptic Type 3C

Synoptic Type 3D
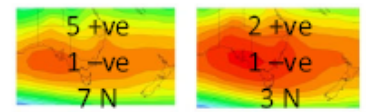

Synoptic Type 4C

Synoptic Type 4D
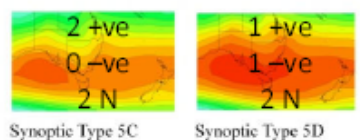

Fig. 8. Number of times each synoptic type has occurred since 1948 on a seasonal basis, stratified into SAM positive (+ve), SAM negative $(-\mathrm{ve})$ and SAM neutral (N) phases. Note: Fig. 3 features a magnified version of the SOM matrix under laying the frequency of occurrence numbers shown here.

gional climate drivers (using SOM). Future work will utilise insights into the links between large-scale climate modes and regional synoptic patterns to better explain (and predict) local-scale climate variability. Future investigation will also involve analysis of the sensitivity of these results to the use of different SLP data sets and/or alternate synoptic typing techniques (similar to Hope et al., 2006) and/or alternate indices to represent large-scale climate modes. It is also worth noting that the methodology used here to identify regionallyspecific climate drivers (and their relationships with large- scale climate modes) could be further used to develop novel GCM/dynamical model performance metrics which would help verify, inform and improve climate modelling so as to provide increased confidence (or at least enable more robust quantification of uncertainty) in future climate projections.

Acknowledgements. This work was partially funded by the Victorian Department of Sustainability and the Environment (DSE). The authors wish to thank Peter Hill (SKM), Rory Nathan (SKM), Rae Moran (DSE) and Shaun Berg (DSE) for their involvement in discussions relating to this paper. 

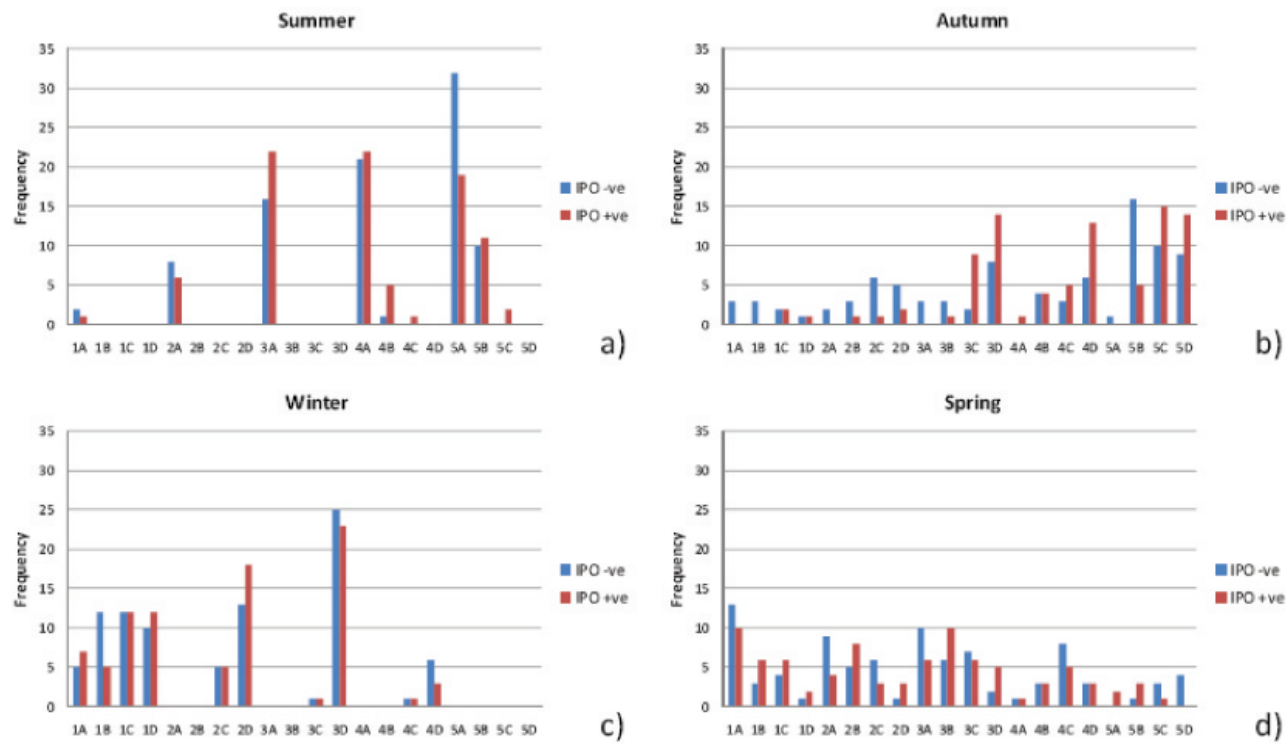

Fig. 9. Number of times each synoptic type has occurred since 1948 on a seasonal basis, stratified into IPO positive (+ve) and IPO negative (-ve) phases for (a) summer, (b) autumn, (c) winter, (d) spring.

Edited by: M. Sivapalan

\section{References}

Ashok, K., Guan, Z., and Yamagata, T.: Influence of the Indian Ocean Dipole on the Australian winter rainfall, Geophys. Res. Lett., 30, doi:10.1029/2003GL017926, 2003.

Cavazos, T.: Using self-organizing maps to investigate extreme climate events: An application to wintertime precipitation in the Balkans, J. Clim., 13, 1718-1732, 2000.

Cavazos, T., Comrie, A. C., and Liverman, D. M.: Intraseasonal variability associated with wet monsoons in southeast Arizona, J. Clim., 15, 2477-2490, 2002.

Chiew, F. H. S., Piechota, T. C., Dracup, J. A., and McMahon, T. A.: El Nino Southern Oscillation and Australian rainfall, streamflow and drought - links and potential for forecasting, J. Hydrol., 204, 138-149, 1998.

Drosdowsky, W.: The latitude of the subtropical ridge over Eastern Australia: The L index revisited, Int. J. Climatol., 25, 12911299, 2005.

Erskine, W. D. and Warner, R. F.: Geomorphic effects of alternating flood and drought dominated regimes on a coastal NSW river, in: Fluvial Geomorphology of Australia, Academic Press, Sydney, Australia, 223-244, 1988.

Folland, C. K., Parker, D. E., Colman, A. W., and Washington, R.: Large scale modes of ocean surface temperature since the late nineteenth century, in: Beyond El Nino: Decadal and Interdecadal Climate Variability, Springer, Berlin, Germany, 73-102, 1999.

Franks, S. W. and Kuczera, G.: Flood frequency analysis: Evidence and implications of secular climate variability, New South Wales, Water Resour. Res., 38(5), doi:10.1029/2001WR000232, 2002.
Hewitson, B. C. and Crane, R. G.: Self-organizing maps: application to synoptic climatology, Clim. Res., 22, 13-26, 2002.

Hope, P. K., Drosdowsky, W., and Nicholls, N.: Shifts in the synoptic systems influencing southwest Western Australia, Clim. Dynam., 26, 751-764, 2006.

Kiem, A. S. and Verdon-Kidd, D. C.: Climatic drivers of Victorian streamflow - is ENSO the dominant influence?, Austr. J. Water Resour., 13(1), 2009.

Kohonen, T.: Self-organizing maps, Springer, New York, USA, 501 pp., 1995.

Mantua, N. J., Hare, S. R., Zhang, Y., Wallace, J. M., and Francis, R. C.: A Pacific decadal climate oscillation with impacts on salmon production, B. Am. Meteor. Soc., 78, 1069-1079, 1997.

McMahon, T. A., Finlayson, B. L., Haines, A. T., and Srikanthan, R.: Runoff variability: a global perspective, in: Influence of Climate Change and Climatic Variability on the Hydrologic Regime and Water Resources, vol. 168. International Association of Hydrological Sciences, Wallingford, England, UK, 3-11, 1987.

Meneghini, B., Simmonds, I., and Smith, I. N.: Association between Australian rainfall and the Southern Annular Mode, Int. J. Climatol., 27, 109-121, 2007.

Murphy, B. F. and Timbal, B.: A review of recent climate variability and climate change in southeastern Australia, Int. J. Climatol., 28, 859-879, 2007.

Nicholls, N.: Sea surface temperatures and Australian winter rainfall, J. Clim., 2, 965-973, 1989.

Nicholls, N., Drosdowsky, W., and Lavery, B.: Australian rainfall variability and change, Weather, 52, 66-72, 1997.

Pook, M. J., McIntosh, P. C., and Meyers, G. A.: The synoptic decomposition of cool-season rainfall in the southeastern Australian cropping region, J. Appl. Meteor. Clim., 45, 1156-1170, 2006.

Power, S., Casey, T., Folland, C., Colman, A., and Mehta, V.: Interdecadal modulation of the impact of ENSO on Australia, Clim. Dynam., 15, 319-324, 1999. 
Power, S., Tseitkin, F., Torok, S., Lavery, B., Dahni, R., and McAvaney, B.: Australian temperature, Australian rainfall and the Southern Oscillation, 1910-1992: coherent variability and recent changes, Australian Meteorological Magazine, 47, 85-101, 1998.

Reusch, D. B., Alley, R. B., and Hewitson, B. C.: North Atlantic climate variability from a self-organizing map perspective, J.. Geophys. Res., 112, D02104, doi:02110.01029/02006JD007460, 2007.

Ropelewski, C. F. and Halpert, M. S.: Global and Regional Scale Precipitation Patterns Associated with the El Niño/Southern Oscillation, Mon. Weather Rev., 115, 1606-1626, 1987.

Saji, H. H., Goswami, B. N., Vinayachandran, P. N., and Yamagata, T.: A dipole mode in the tropical Indian Ocean, Nature, 401, 360-363, 1999.

Stone, R. and Auliciems, A.: SOI Phase relationships with rainfall in eastern Austalia, Int. J. Climatol., 12, 625-636, 1992.

Sturman, A. and Tapper, N.: The Weather and Climate of Australia and New Zealand, Oxford University Press, Melbourne, Victoria, Australia, 2004.

Tapper, N. and Hurry, L.: Australia's Weather Patterns - An Introductory Guide, Dellasta Pty Ltd., Mount Waverly, Victoria, 1996.

Thompson, D. W. J. and Wallace, J. M.: Annular modes in the extratropical circulation, part I: month-to-month variability, J. Clim., 13, 1000-1016, 2000.
Timbal, B. and Jones, D. A.: Future projections of winter rainfall in southeast Australia using a statistical downscaling technique, Clim. Change, 86, 165-187, 2008.

Verdon, D. C. and Franks, S. W.: Indian Ocean sea surface temperature variability and winter rainfall: Eastern Australia, Water Res. Res., 41, W09413, doi:09410.01029/02004WR003845, 2005.

Verdon, D. C. and Franks, S. W.: Long-term behaviour of ENSO: Interactions with the PDO over the past 400 years inferred from paleoclimate records, Geophys. Res. Lett., 33, L06712, doi:10.1029/2005GL025052, 2006.

Verdon, D. C., Wyatt, A. M., Kiem, A. S., and Franks, S. W.: Multi-decadal variability of rainfall and streamflow - Eastern Australia, Water Res. Res., 40, W10201, doi:10210.11029/12004WR003234, 2004.

Wright, W. J.: A synoptic climatological classification of winter precipitation in Victoria, Australian Meteorological Magazine, 37, 217-229, 1989.

Zanchettin, D., Franks, S. W., Traverso, P., and Tomasino, M.: On ENSO impacts on European wintertime rainfalls and their modulation by the NAO and the Pacific multi-decadal variability described through the PDO index, Int. J. Climatol., 28, 995-1006, 2008 . 